\title{
Glucose Control Predicts 2-Year Change in Lipid Profile in Youth with Type 1 Diabetes
}

\author{
DM Maahs, MD, PhD1,2,3, D Dabelea, MD, PhD², RB. D'Agostino Jr, $\mathrm{PhD}^{4}$, JS. Andrews, \\ $\mathbf{M S}^{4}$, AS Shah, $\mathbf{M D}^{5}, \mathbf{N}$ Crimmins, $\mathbf{M D}^{5}$, EJ. Mayer-Davis, $\mathbf{P h D}^{6}, \mathbf{S}$ Marcovina, $\mathbf{P h D}^{7}, \mathbf{G}$ \\ Imperatore, MD, $\mathrm{PhD}^{8}$, RP Wadwa, $\mathrm{MD}^{1}$, SR Daniels, $\mathrm{MD}, \mathrm{PhD}^{3}, \mathrm{~K}$ Reynolds, $\mathrm{MPH} \mathrm{PhD}^{9}$, $\mathrm{RF}$ \\ Hamman, MD, DrPH ${ }^{2}$, and LM Dolan, MD ${ }^{5}$ for the SEARCH for Diabetes in Youth Study ${ }^{*}$ \\ ${ }^{1}$ Barbara Davis Center for Childhood Diabetes, University of Colorado Denver, Aurora, CO \\ ${ }^{2}$ Colorado School of Public Health, Department of Epidemiology, University of Colorado Denver \\ ${ }^{3}$ The Children's Hospital Colorado, Aurora, CO \\ ${ }^{4}$ Wake Forest School of Medicine, Winston-Salem, NC \\ ${ }^{5}$ Cincinnati Children's Hospital, University of Cincinnati College of Medicine, Cincinnati, $\mathrm{OH}$ \\ ${ }^{6}$ University of North Carolina, School of Medicine, Chapel Hill, NC \\ ${ }^{7}$ Northwest Lipid Research Laboratory, Seattle, WA \\ ${ }^{8}$ Division of Diabetes Translation, The Centers for Disease Control and Prevention, Atlanta, GA \\ ${ }^{9}$ Department of Research \& Evaluation, Kaiser Permanente Southern California Pasadena, CA
}

\section{Abstract}

Objective-To test the hypothesis that a change in A1c over a follow-up interval of approximately 2 years would be associated with concomitant changes in fasting lipids in individuals with type 1 diabetes (T1D).

Study design-All subjects with T1D diagnosed 2002-2005 in the SEARCH for Diabetes in Youth study with at least two study visits approximately 12 and 24-months after an initial visit were included (age at initial visit $=10.6 \pm 4.1$ years, $48 \%$ female, diabetes duration $=10 \pm 7$ months, $76 \%$ non-Hispanic White, A1c=7.7 $\pm 1.4 \%$ ). Longitudinal mixed models were fit to examine the relationship between change in A1c and change in lipid levels (total cholesterol [TC], high-density lipoprotein-cholesterol [HDL-c], low-density lipoprotein-cholesterol [LDL-c], log triglycerides [TG], and non-high-density lipoprotein-cholesterol [non-HDL-c]) with adjustment for possible confounders.

(C) 2012 Mosby, Inc. All rights reserved.

Address all correspondence to: David M. Maahs, M.D., PhD, Barbara Davis Center for Diabetes, University of Colorado Denver, PO Box 6511, Mail Stop A140, Aurora, CO 80045, Phone: 303-724-2323, Fax: 303-724-6779, David.Maahs@ucdenver.edu.

*A list of members of the SEARCH for Diabetes in Youth Study and funding information are available at www.jpeds.com (Appendix).

The contents of this paper are solely the responsibility of the authors and do not necessarily represent the official views of the Centers for Disease Control and Prevention and the National Institute of Diabetes and Digestive and Kidney Diseases. D.M. and R.W. have had a research grant from Merck for a clinical trial of lipid-lowering medications in youth with type 1 diabetes. The other authors declare no conflicts of interest.

Presented in abstract form at the American Diabetes Association Scientific Session in New Orleans, LA, June 2009.

Publisher's Disclaimer: This is a PDF file of an unedited manuscript that has been accepted for publication. As a service to our customers we are providing this early version of the manuscript. The manuscript will undergo copyediting, typesetting, and review of the resulting proof before it is published in its final citable form. Please note that during the production process errors may be discovered which could affect the content, and all legal disclaimers that apply to the journal pertain. 
Results-Change in A1c over time was significantly associated with changes in TC, HDL-c, LDL-c, TG, and non-HDL-c over the range of A1c values. For example, for a person with an A1c of $10 \%$ and then a $2 \%$ decrease in A1c 2-years later (to 8\%), the model predicted concomitant changes in TC $(-0.29 \mathrm{mmol} / 1,-11.4 \mathrm{mg} / \mathrm{dl}), \mathrm{HDL}-\mathrm{c}(0.03 \mathrm{mmol} / \mathrm{l}, 1.3 \mathrm{mg} / \mathrm{dl})$, LDL-c $(-0.23$ $\mathrm{mmol} / \mathrm{l},-9.0 \mathrm{mg} / \mathrm{dl})$, and non-HDL-c $(-0.32 \mathrm{mmol} / \mathrm{l},-12.4 \mathrm{mg} / \mathrm{dl})$, and an $8.5 \%$ decrease in TG $(\mathrm{mmol} / \mathrm{l})$.

Conclusions-Improved glucose control over a 2-year follow-up was associated with a more favorable lipid profile, but may be insufficient to normalize lipids in dyslipidemic T1D youth needing to decrease lipids to goal.

\section{Key Terms}

cholesterol; lipids; glycemic control; pediatrics; type 1 diabetes; cardiovascular disease risk factors; diabetes mellitus; epidemiology

Hyperglycemia and dyslipidemia are metabolic abnormalities commonly found in individuals with type 1 diabetes (T1D). Both increase the risk of cardiovascular disease (CVD), the leading cause of mortality in individuals with T1D (1).

The antecedents of adult CVD, including dyslipidemia, are present in children and numerous studies demonstrate tracking of CVD risk factors into adulthood (2-4). Furthermore, CVD risk factors in childhood are associated with both surrogate markers of atherosclerosis (4) and atherosclerotic lesions at autopsy in adults (2;3). Due to these findings the American Diabetes Association (ADA) (5), the American Academy of Pediatrics (AAP) (6), the International Society of Pediatric and Adolescent Diabetes (ISPAD) (7), and the American Heart Association (AHA) (8) have all published guidelines for intervention in youth with diabetes and dyslipidemia. However, because there is a paucity of data on dyslipidemia in youth with T1D, these guidelines are based on extrapolation of data from adults and from youth without diabetes (1).

Each of these professional organizations recommends intensification of glucose control, a healthy diet, and exercise as the initial therapy for dyslipidemia in youth with T1D. However, it is unclear to what extent improved glucose control alters lipid measurements. Better understanding of the association of glucose control to dyslipidemia would inform current practice guidelines and clinical decision making about the treatment of dyslipidemia in youth with T1D (1). Therefore, we tested the hypothesis that a change in glycated hemoglobin (A1c) over a follow-up interval of approximately 2 years would be associated with concomitant changes in the lipid profile in youth with T1D participating in the SEARCH for Diabetes in Youth (SEARCH) study.

\section{Methods}

SEARCH is an ongoing study that began in 2001 to conduct population-based case ascertainment of youth $<20$ years with diabetes (9). SEARCH has a defined protocol for incident cases to have 12- and 24-month follow-up visits after their initial study visit. This paper includes information for the participants in the 2002-2005 incident cohorts and the corresponding 12- and 24-month visits for participants with at least one follow-up visit after the initial study visit. The study was reviewed and approved by the local institutional review boards that had jurisdiction over the local study populations and all participants provided informed consent and/or assent.

During the study visit, survey information, including medication use, was collected, an examination was performed to measure systolic and diastolic blood pressure, height, weight, 
BMI, and waist circumference, as previously described (9) and blood samples were obtained under conditions of metabolic stability after at least eight hours of fasting. Specimens were processed locally at the sites and within 24 hours shipped to the central laboratory (Northwest Lipid Metabolism and Diabetes Research Laboratories, University of Washington, Seattle) where they were analyzed for measurement of total cholesterol (TC), high-density lipoprotein cholesterol (HDL-c), and triglycerides (TG). Measurements of TC, HDL-c, and TG were performed enzymatically using Roche reagent on a Hitachi Modular P autoanalyzer (Roche Diagnostics, Indianapolis, IN). Low-density lipoprotein cholesterol (LDL-c), levels were calculated by the Friedewald equation for individuals with TG levels less than $4.52 \mathrm{mmol} / \mathrm{l}$ and by Lipid Research Clinics Beta Quantification for those with triglyceride levels at least $4.52 \mathrm{mmol} / \mathrm{l}$. Non-HDL-c concentration was computed as TC minus HDL-c. A1c levels were measured by ion-exchange high-performance liquid chromatography (TOSOH G7, TOSOH Biosciences Inc., South San Francisco, CA).

The diabetes type was categorized as type 1 and type 2, based on the health care provider diagnosis (9). Race/ethnicity was self-reported using the 2000 census questionnaire format. Five categories were created (Hispanic, American Indian, non-Hispanic Black, Asian/Pacific Islander, non-Hispanic White [NHW]).

The study population consisted of all SEARCH participants with T1D who were diagnosed from 2002 through 2005 and had at least two study visits where fasting lipids and A1c were measured simultaneously. Subjects reporting use of lipid-lowering medications $(n=7)$ were excluded. Of the 1,193 participants included in these analyses, fasting lipids were measured in all twice, and in 563 three times over an approximately 24-month period. Subjects were invited to a SEARCH visit only after diabetes has been diagnosed and no patients in DKA were included in the analyses.

\section{Statistical Analyses}

The mean and SD (or median and Q1, Q3) for each variable of interest were calculated based on data collected at the initial visit. Longitudinal mixed models using all data from the initial and subsequent visits were fit to examine the relationship between A1c (initial value and time-varying values) and time-varying lipid levels (TC, HDL-c, LDL-c, TG, and nonHDL-c) included as the outcome in each model. As a marker of time for each participant, we included duration of diabetes (number of months since diabetes diagnosis) in these mixed models. Because this study is observational all assessments of the lipid measures (baseline and follow-up) are contained in our statistical models as part of the outcome.

Multivariable modeling focused on the effects of the initial A1c (measured at the first SEARCH study visit) and the time-varying effects of A1c measured at the 12- and/or 24month follow-up visits. In addition we explored any interaction of the main effects. Each model also included several participant-level characteristics that were measured at the initial visit as covariates. These effects included participant age (included as age and age-squared to allow for non-linear relationships), race/ethnicity (NHW vs other groups), sex, site, season of the year when measurements were performed (autumn vs each other season), and baseline BMI z-score (BMI value represented as a z-score that adjusts for age and sex for each participant) Because Tanner Staging was not available for all participants due to IRB restrictions at some centers, we examined the correlation between Tanner Staging (where available) and participant age. We found these two measures were highly correlated ( $\mathrm{r}=0.84$, $\mathrm{p}<0.0001$ ), thus the inclusion of age in the above models was also considered a surrogate for pubertal stage.

For multivariable models, the beta-coefficient and 95\% confidence intervals (CI) for the association of time varying A1c (to determine the association of change in A1c with change 
in lipid) adjusted for initial A1c and diabetes duration are reported (adjusted for age, agesquared, race/ethnicity, sex, site, season of the year, and baseline BMI z-score. Additionally, an interaction term (initial A1c by time varying A1c) was included in this model to determine whether the association of change in A1c with changes in lipids was different depending on the initial A1c value. All statistical analyses were conducted using SAS software, version 9.2 (SAS Institute, Cary, NC, USA).

\section{Results}

The clinical characteristics of 1,193 individuals at the initial visit are described in Table I (age $=10.6 \pm 4.1$ years, $48 \%$ female, T1D duration $=10 \pm 7$ months, $76 \%$ non-Hispanic White, $\mathrm{A} 1 \mathrm{c}=7.7 \pm 1.4 \%$ ). Mean and SD for fasting lipid measures at the initial visit were: TC $4.17 \pm 0.76 \mathrm{mmol} / \mathrm{l}$ or $161 \pm 29 \mathrm{mg} / \mathrm{dl}$, HDL-c $1.39 \pm 0.33 \mathrm{mmol} / \mathrm{l}$ or $54 \pm 13 \mathrm{mg} / \mathrm{dl}$, LDL-c $2.45 \pm 0.63 \mathrm{mmol} / \mathrm{l}$ or $95 \pm 24 \mathrm{mg} / \mathrm{dl}$, TG [median $(\mathrm{Q} 1, \mathrm{Q} 3)] 0.62(0.50,0.81) \mathrm{mmol} / \mathrm{l}$ or 55 $(42,72) \mathrm{mg} / \mathrm{dl}$, and non-HDL-c $2.78 \pm 0.69 \mathrm{mmol} / \mathrm{l}$ or $108 \pm 27 \mathrm{mg} / \mathrm{dl}$. Mean $\pm \mathrm{SD}$ annualized change in $\mathrm{A} 1 \mathrm{c}$ was $0.45 \pm 0.89 \%$ and mean $\pm \mathrm{SD}$ annualized change in each fasting lipid measure were TC $(0.08 \pm 0.41 \mathrm{mmol} / \mathrm{L}, 3.0 \pm 15.7 \mathrm{mg} / \mathrm{dl})$, HDL-c $(0.03 \pm 0.17 \mathrm{mmol} / \mathrm{L}, 1.2 \pm 6.5$ $\mathrm{mg} / \mathrm{dl}), \mathrm{LDL}-\mathrm{c}(0.02 \pm 0.30 \mathrm{mmol} / \mathrm{L}, 0.7 \pm 11.6 \mathrm{mg} / \mathrm{dl}), \mathrm{TG}(0.07 \pm 0.36 \mathrm{mmol} / \mathrm{L}, 5.7 \pm 31.8 \mathrm{mg} /$ $\mathrm{dl})$ and non-HDL-c $(0.05 \pm 0.35 \mathrm{mmol} / \mathrm{L}, 1.7 \pm 13.5 \mathrm{mg} / \mathrm{dl})$. Using cut-points of TC $200 \mathrm{mg} / \mathrm{dl}$, LDL-c 130 and $100 \mathrm{mg} / \mathrm{dl}$, HDL-c $35 \mathrm{mg} / \mathrm{dl}$, non-HDL-c $160 \mathrm{mg} / \mathrm{dl}$, and TG 150mg/dl, then the rates of abnormalities at the initial visit for this analysis are $8.4 \%, 7.2 \%$ and $37.1 \%$, $4.7 \%, 3.1 \%$ and $2.9 \%$, respectively.

Change in A1c was associated with changes in TC, HDL-c, LDL-c, TG, and non-HDL-c over the range of A1c values in these data The interaction term between initial $\mathrm{A} 1 \mathrm{c}$ and time varying A1c was significant $(\mathrm{p}<0.01$ ) for TC, HDL-c, $\log \mathrm{TG}$, and non-HDL-c and $\mathrm{p}=0.0506$ for LDL-c, although because this was a test for an interaction rather than a main effect, this p-value is likely to also be clinically significant. This indicates that the effect of changing A1c on changes in lipid values over time differed based on the initial A1c values (Table II). For example, for a decrease in A1c from $10 \%$ at 6-months duration to $8 \%$ two years later ( $2 \%$ of subjects had a $2 \%$ change in A1c from first to last measure), the model predicted a change in TC $(-8.5 \mathrm{mg} / \mathrm{dL},-0.29 \mathrm{mmol} / 1,95 \% \mathrm{CI}:-0.37,-0.22$ or $-11.4,95 \%$ CI: -14.3$)$, HDL-c $(2.5 \mathrm{mg} / \mathrm{dL}, 0.03 \mathrm{mmol} / 1,95 \%$ CI: $0.00,0.07$ or $1.3,95 \%$ CI: 0.03$)$, LDL-c (-6.8 $\mathrm{mg} / \mathrm{dL},-0.23 \mathrm{mmol} / \mathrm{l}, 95 \% \mathrm{CI}:-0.29,-0.17$ or $-9.0,95 \% \mathrm{CI}:-11.3)$, and non-HDL-c $(-9.7$ $\mathrm{mg} / \mathrm{dL},-0.32 \mathrm{mmol} / \mathrm{l}, 95 \% \mathrm{CI}:-0.39,-0.25$ or $-12.4,95 \% \mathrm{CI}:-15.0)$, and a $8.46 \%(95 \%$ CI: $3.96 \%, 12.76 \%$ ) decrease in TG. These associations were independent of initial age, race/ethnicity, sex, season of the year, diabetes duration, and BMI z-score. Of the 145 subjects with an initial LDL-c $>100 \mathrm{mg} / \mathrm{dl}$ who also had a decrease in A1c, $48(33 \%)$ had an LDL-c $<100 \mathrm{mg} / \mathrm{dl}$ at the last measure.

The Figure illustrates the varying changes in lipid values over a 24 month interval (with a starting duration of 6 months) for a range of starting and ending A1c values. They are based on the results of the adjusted multivariate model (Table II) and display the predicted mean changes in lipid level associated with a $2 \%$ or $1 \%$ decrease or increase in A1c over 24months (starting at 6-months duration) for a starting A1c level of $8 \%$ (in the first column) or $10 \%$ (in the second column). For example, for an initial A1c of $8 \%$, a decrease in A1c of $2 \%$ and $1 \%$ would result in a predicted change in TC of $-0.24 \pm 0.03 \mathrm{mmol} / \mathrm{L}(-9.3 \pm 1.3 \mathrm{mg} / \mathrm{dl})$ and $-0.10 \pm 0.03 \mathrm{mmol} / \mathrm{L}(-3.9 \pm 1.0 \mathrm{mg} / \mathrm{dl})$, respectively, and an increase of $1 \%$ and $2 \%$ would result in a predicted change of $0.18 \pm 0.02 \mathrm{mmol} / \mathrm{L}(6.9 \pm 0.7 \mathrm{mg} / \mathrm{dl})$ and $0.32 \pm 0.02$ $\mathrm{mmol} / \mathrm{L}(12.3 \pm 0.9 \mathrm{mg} / \mathrm{dl})$, respectively.

We also found that the association of change in A1c to changes in lipids over time was nonsymmetric. Thus, the models predict the following. First, change in A1c in subjects with a 
higher initial A1c will have larger effects on change in TC, non-HDL-c, and TG (in either direction) compared with subjects with lower initial A1c. Second, the association of change in A1c to change in TC, HDL-c, and TG over 2-years is larger for those subjects who have an increasing A1c as compared with those who have a decreasing A1c (Figure).

Although the focus of this paper is on the association of change in A1c to changes in lipids, some initial visit covariates were independently associated with lipid outcomes. Higher BMI z-score was associated with lower HDL-c, and higher LDL-c, TG and non-HDL-c. Female sex was associated with higher TC, LDL-c, TG, and non-HDL-c. Non-Hispanic Black race/ ethnicity (compared with NHW) was associated with higher HDL-c and lower TG and nonHDL-c. For LDL-c and non-HDL-c the quadratic term for age was significant and positive with a significant negative linear age effect, and estimates suggest a negative association between age and lipid for younger ages followed by a reversal to a positive association for older ages. In contrast, for HDL-c the quadratic term for age was significant and negative, with a significant positive linear effect, with estimates suggesting an initial positive relationship at younger ages with a reversal to a negative association at older ages.

\section{Discussion}

We demonstrate that change in glucose control is associated with changes in lipids over a period of approximately 2 years in youth with T1D. This relationship remains after controlling for the effects of initial age, race/ethnicity, sex, season of the year, T1D duration, and BMI z-score. These data suggest that improvement of glucose control in youth with T1D may have a limited (i.e. a decrease of $0.23 \mathrm{mmol} / \mathrm{L}$ in LDL-c associated with a decrease in A1c from $10 \%$ to $8 \%$ over 2 years), though beneficial effect on TC, HDL-c, TG, LDL-c and non-HDL-c. Thus, these data provide additional support for the current AHA, ADA, AAP, and ISPAD guidelines which recommend intensification of glucose control, in addition to a healthy diet and lifestyle, as the initial steps to treat dyslipidemia.

There are additional clinical implications of these findings. First, changes in A1c in patients with higher initial A1c will have larger effects on TC, non-HDL-c, and TG levels as compared with similar A1c changes in patients with lower initial A1c. Second, the associations of A1c change and changes in lipid levels is greater if A1c worsens than if A1c improves (for TC, HDL, and TG). These data are consistent with the concept of metabolic memory (10) such that increases in A1c could exert an atherogenic effect via the effect of hyperglycemia on lipids. Although some of these associations between A1c change and changes in lipid levels may be small clinically it is possible that even small changes in lipid levels may have negative health impact over time with prolonged duration of diabetes. It is also possible that for those patients with higher initial A1c additional healthy behaviors such as diet and exercise contributed to the larger effects on decrease in TC, non-HDL-c, and TG.

In these analyses, sex, age, race/ethnicity, and BMI z-score were also associated with change in lipids. Of these, only BMI is a modifiable risk factor for dyslipidemia. We found that a higher BMI z-score at baseline was associated with unfavorable changes in HDL-c, LDL-c, TG, and non-HDL-c, independent of glycemic control. This finding emphasizes the importance of weight control in youth with T1D. However, intensification of glucose control may also have an adverse effect on BMI and the lipid profile. Specifically, the Diabetes Control and Complications Trial (DCCT) study, which was predominantly a study of adults with T1D, reported that an increase in BMI was associated with a worsening in lipids in the intensive vs the conventionally treated groups (11), although a clinical trial in T1D adults has shown the feasibility of reducing A1c without increasing BMI (12). Furthermore, although improving glucose control is always one of the primary goals of care for persons with T1D and their diabetes care providers, based on these data improved glucose control 
alone may not be sufficient to achieve lipids goals (i.e., a decrease of $0.23 \mathrm{mmol} / \mathrm{L}$ [ $9 \mathrm{mg} / \mathrm{dl}$ ] in LDL-c associated with a decrease in A1c from $10 \%$ to $8 \%$ over 2 years). Similarly, in the Coronary Artery Calcification in Type 1 Diabetes (CACTI) study in adults with a longer duration of T1D, change in A1c was associated with significant changes in TC, LDL-c, TG, and non-HDL-c (but not HDL-c) over 6-years (13). However, in the CACTI study treatment with dyslipidemia medication eliminated statistical significance of the association of A1c to lipids as these medications had a stronger effect on lipids than did glycemic control. Understanding the complex interaction among A1c, BMI, and lipids and how these factors influence the development and progression of CVD in people with T1D requires further study.

These longitudinal data are consistent with previous smaller cross-sectional studies in youth with T1D in which a correlation between A1c and a more atherogenic lipid profile was found (14-17). The DCCT reported that TC, LDL-c, and TG increased with elevated A1c, but HDL-c was not correlated with A1c (18). In addition, a recent study from adolescents in the UK reported a significant positive association of glycemia to TC, TG, LDL-c, and nonHDL-c (19). However, a limitation of the UK study was that the participants were not fasting, calling into question the validity of the TG and LDL-c measures, although recent data suggest that the differences in fasting compared with non-fasting lipid profiles may not be clinically significant (20). Other longitudinal studies in youth reported similar results but in smaller samples $(21 ; 22)$ or using retrospective data $(23)$. Further, pre-DCCT data (cohort of 212 subjects with T1D with a mean age 22 years) reported a $2.2 \%$ and $8 \%$ decrease in TC and TG, respectively, per $1 \%$ point decrease in A1c over an average interval of 3.7 years (24). Data on HDL-c, LDL-c, and non-HDL-c were not reported in that study. Another preDCCT study (mean A1c=14.2 $\pm 2.1 \%$ ) reported covariations in A1c and lipid levels (25). Thus, the literature supports concomitant changes in A1c and lipid measures and our data confirm and add additional dimensions to these previous findings.

In contrast to our findings, a previous SEARCH publication using cross-sectional analysis did not find an association between A1c and HDL-c (16) and a recent UK study of adolescents reported no association of glycemia and HDL-c (19). Purnell et al reported that intensive insulin therapy in the DCCT resulted in lower A1c and lower HDL-c associated with increased BMI (11) and suggest that concomitant changes in glucose control and HDLc may be mediated by factors affecting insulin resistance (26). This possibility is supported by the association of insulin resistance (measured by a hyperinsulinemic-euglycemic clamp) with higher TG and TG/HDL-c in both adolescents and adults and lower HDL-c in adolescents with T1D(27). Similarly, in subjects with T1D, more insulin resistance was associated with a proatherogenic lipoprotein subfraction cholesterol distribution (28). Investigators have reported higher HDL-c concentrations in adults (29) and youth (17) with T1D than in non-diabetic controls. In a post-hoc analysis, units of insulin $/ \mathrm{kg} / \mathrm{day}$ was not significantly associated with changes in lipids. More research is needed to clarify the complex relationship between glucose control and HDL-c in T1D.

Our study has some limitations. First, the data are observational and not the result of a randomized clinical trial nor can we comment on the duration of A1c change to changes in lipids. We also do not have follow-up data or Tanner stage data on all participants.

However, minimal differences existed between those who did and did not participate in the follow-up assessment. Also, the study was conducted on a cohort of youth recently diagnosed with T1D (diabetes duration $10 \pm 7$ months at baseline) of whom many likely had residual beta-cell function, which may limit A1c variability. Finally, although the SEARCH study population includes an ethnic representation that is consistent with the ethnic diversity in the United States, SEARCH does not represent all of the geographic areas in the United States nor does it account for regional ethnic diversity and does not focus on racial-ethnic 
differences in lipids (30). Thus, these findings may not apply to all populations in the United States or other populations worldwide.

In conclusion, improved glucose control in youth with T1D was associated with more favorable TC, HDL-c, TG, LDL-c, and non-HDL-c levels over a 2-year follow-up. However, reduction in A1c may be insufficient to normalize lipids in dyslipidemic T1D youth needing to decrease lipids to goal. Although longitudinal studies of lipids in youth with T1D $(21 ; 23)$ have been published, we investigated the relationship between the change in glucose control and changes in fasting lipids in a large cohort of youth with T1D. We also report that the association of change in A1c to changes in lipids is more pronounced with higher initial A1c values and for increases as compared with decreases in A1c. Further research is needed to establish the roles of glucose control, diet, exercise, and dyslipidemia medications to improve the cardiovascular health of youth with T1D.

\section{Acknowledgments}

The SEARCH for Diabetes in Youth Study is indebted to the many youth and their families, and their health care providers, whose participation made this study possible.

\section{Reference List}

1. Maahs DM, Wadwa RP, Bishop F, Daniels SR, Rewers M, Klingensmith GJ. Dyslipidemia in youth with diabetes: to treat or not to treat? J Pediatr. 2008 Oct; 153(4):458-65. [PubMed: 18847618]

2. McGill HC Jr, McMahan CA, Malcom GT, Oalmann MC, Strong JP. Effects of serum lipoproteins and smoking on atherosclerosis in young men and women. The PDAY Research Group. Pathobiological Determinants of Atherosclerosis in Youth. Arterioscler Thromb Vasc Biol. 1997 Feb; 17(1):95-106. [PubMed: 9012643]

3. Berenson GS, Srinivasan SR, Bao W, Newman WP III, Tracy RE, Wattigney WA. Association between multiple cardiovascular risk factors and atherosclerosis in children and young adults. The Bogalusa Heart Study [see comments]. N Engl J Med. 1998 Jun 4; 338(23):1650-6. [PubMed: 9614255]

4. Raitakari OT, Juonala M, Kahonen M, Taittonen L, Laitinen T, Maki-Torkko N, Jarvisalo MJ, Uhari M, Jokinen E, Ronnemaa T, Akerblom HK, Viikari JS. Cardiovascular risk factors in childhood and carotid artery intima-media thickness in adulthood: the Cardiovascular Risk in Young Finns Study. JAMA. 2003 Nov 5; 290(17):2277-83. [PubMed: 14600186]

5. Silverstein J, Klingensmith G, Copeland K, Plotnick L, Kaufman F, Laffel L, Deeb L, Grey M, Anderson B, Holzmeister LA, Clark N. Care of children and adolescents with type 1 diabetes: a statement of the American Diabetes Association. Diab care. 2005 Jan; 28(1):186-212.

6. Daniels SR, Greer FR. Lipid screening and cardiovascular health in childhood. peds. 2008 Jul; 122(1):198-208.

7. Donaghue KC, Chiarelli F, Trotta D, Allgrove J, hl-Jorgensen K. ISPAD clinical practice consensus guidelines 2006-2007. Microvascular and macrovascular complications. Pediatr Diabetes. 2007 Jun; 8(3):163-70. [PubMed: 17550427]

8. McCrindle BW, Urbina EM, Dennison BA, Jacobson MS, Steinberger J, Rocchini AP, Hayman LL, Daniels SR. Drug therapy of high-risk lipid abnormalities in children and adolescents: a scientific statement from the American Heart Association Atherosclerosis, Hypertension, and Obesity in Youth Committee, Council of Cardiovascular Disease in the Young, with the Council on Cardiovascular Nursing. Circulation. 2007 Apr 10; 115(14):1948-67. [PubMed: 17377073]

9. Dabelea D, Bell RA, D’Agostino RB Jr, Imperatore G, Johansen JM, Linder B, Liu LL, Loots B, Marcovina S, Mayer-Davis EJ, Pettitt DJ, Waitzfelder B. Incidence of diabetes in youth in the United States. JAMA. 2007 Jun 27; 297(24):2716-24. [PubMed: 17595272]

10. Sustained effect of intensive treatment of type 1 diabetes mellitus on development and progression of diabetic nephropathy: the Epidemiology of Diabetes Interventions and Complications (EDIC) study. JAMA. 2003 Oct 22; 290(16):2159-67. [PubMed: 14570951] 
11. Purnell JQ, Hokanson JE, Marcovina SM, Steffes MW, Cleary PA, Brunzell JD. Effect of excessive weight gain with intensive therapy of type 1 diabetes on lipid levels and blood pressure: results from the DCCT. Diabetes Control and Complications Trial. JAMA. 1998 Jul 8; 280(2): 140-6. [PubMed: 9669786]

12. Brown RJ, Wijewickrama RC, Harlan DM, Rother KI. Uncoupling intensive insulin therapy from weight gain and hypoglycemia in type 1 diabetes. Diabetes Technol Ther. 2011 Apr; 13(4):45760. [PubMed: 21355723]

13. Maahs DM, Ogden LG, Dabelea D, Snell-Bergeon JK, Daniels SR, Hamman RF, Rewers M. Association of glycaemia with lipids in adults with type 1 diabetes: modification by dyslipidaemia medication. diabetol. 2010 Dec; 53(12):2518-25.

14. Maahs DM, Maniatis AK, Nadeau K, Wadwa RP, McFann K, Klingensmith GJ. Total cholesterol and high-density lipoprotein levels in pediatric subjects with type 1 diabetes mellitus. J Pediatr. 2005 Oct; 147(4):544-6. [PubMed: 16227045]

15. Kershnar AK, Daniels SR, Imperatore G, Palla SL, Petitti DB, Pettitt DJ, Marcovina S, Dolan LM, Hamman RF, Liese AD, Pihoker C, Rodriguez BL. Lipid abnormalities are prevalent in youth with type 1 and type 2 diabetes: The search for diabetes in youth study. J Pediatr. 2006 Sep; 149(3): 314-9. [PubMed: 16939739]

16. Petitti DB, Imperatore G, Palla SL, Daniels SR, Dolan LM, Kershnar AK, Marcovina S, Pettitt DJ, Pihoker C. Serum lipids and glucose control: the SEARCH for Diabetes in Youth study. Arch Pediatr Adolesc Med. 2007 Feb; 161(2):159-65. [PubMed: 17283301]

17. Guy J, Ogden L, Wadwa RP, Hamman RF, Mayer-Davis EJ, Liese AD, D’ Agostino R Jr, Marcovina S, Dabelea D. Lipid and lipoprotein profiles in youth with and without type 1 diabetes: the SEARCH for Diabetes in Youth case-control study. Diab care. 2009 Mar; 32(3):416-20.

18. Lipid and lipoprotein levels in patients with IDDM diabetes control and complication. Trial experience. The DCCT Research Group. Diab care. 1992 Jul; 15(7):886-94.

19. Loredana MM, Neil DR, Toby PA, Acerini CL, Barrett TG, Cooper JD, Edge J, Neil A, Shield J, Widmer B, Todd JA, Dunger DB. Prevalence of abnormal lipid profiles and the relationship with the development of microalbuminuria in adolescents with type 1 diabetes. Diab care. 2009 Apr; 32(4):658-63.

20. Schwab KO, Doerfer J, Naeke A, Rohrer T, Wiemann D, Marg W, Hofer SE, Holl RW. Influence of food intake, age, gender, HbA1c, and BMI levels on plasma cholesterol in 29,979 children and adolescents with type 1 diabetes--reference data from the German diabetes documentation and quality management system (DPV). Pediatr Diabetes. 2009 May; 10(3):184-92. [PubMed: 19175904]

21. Lopes-Virella MF, Wohltmann HJ, Mayfield RK, Loadholt CB, Colwell JA. Effect of metabolic control on lipid, lipoprotein, and apolipoprotein levels in 55 insulin-dependent diabetic patients. A longitudinal study. diab. 1983 Jan; 32(1):20-5.

22. Reh CM, Mittelman SD, Wee CP, Shah AC, Kaufman FR, Wood JR. A longitudinal assessment of lipids in youth with type 1 diabetes. Pediatr Diabetes. 2011 Jun; 12(4 Pt 2):365-71. [PubMed: 21392191]

23. Maahs DM, Wadwa RP, McFann K, Nadeau K, Williams MR, Eckel RH, Klingensmith GJ. Longitudinal lipid screening and use of lipid-lowering medications in pediatric type 1 diabetes. J Pediatr. 2007 Feb; 150(2):146-50. 150. [PubMed: 17236891]

24. Ostlund RE Jr, Semenkovich CF, Schechtman KB. Quantitative relationship between plasma lipids and glycohemoglobin in type I patients. Longitudinal study of 212 patients. Diab care. 1989 May; 12(5):332-6.

25. Sosenko JM, Breslow J, Miettinen OS, Gabbay KH. Hyperglycemia and plasma lipid levels: covariations in insulin-dependent diabetes. Diab care. 1982 Jan; 5(1):40-3.

26. Purnell JQ, Dev RK, Steffes MW, Cleary PA, Palmer JP, Hirsch IB, Hokanson JE, Brunzell JD. Relationship of family history of type 2 diabetes, hypoglycemia, and autoantibodies to weight gain and lipids with intensive and conventional therapy in the Diabetes Control and Complications Trial. diab. 2003 Oct; 52(10):2623-9.

27. Maahs DM, Nadeau K, Snell-Bergeon JK, Schauer I, Bergman B, West NA, Rewers M, Daniels SR, Ogden LG, Hamman RF, Dabelea D. Association of insulin sensitivity to lipids across the 
lifespan in people with Type 1 diabetes. Diabet Med. 2011 Feb; 28(2):148-55. [PubMed: 21219421]

28. Maahs DM, Hokanson JE, Wang H, Kinney GL, Snell-Bergeon JK, East A, Bergman BC, Schauer IE, Rewers M, Eckel RH. Lipoprotein subfraction cholesterol distribution is proatherogenic in women with type 1 diabetes and insulin resistance. diab. $2010 \mathrm{Jul}$; 59(7):1771-9.

29. Wadwa RP, Kinney GL, Maahs DM, Snell-Bergeon J, Hokanson JE, Garg SK, Eckel RH, Rewers M. Awareness and treatment of dyslipidemia in young adults with type 1 diabetes. Diab care. 2005 May; 28(5):1051-6.

30. Giannini C, Santoro N, Caprio S, Kim G, Lartaud D, Shaw M, Pierpont B, Weiss R. The triglyceride-to-HDL cholesterol ratio: association with insulin resistance in obese youths of different ethnic backgrounds. Diab care. 2011 Aug; 34(8):1869-74.

\section{Appendix}

SEARCH for Diabetes in Youth is funded by the Centers for Disease Control and Prevention (PA numbers 00097, DP-05-069, and DP-10-001), the National Institute of Diabetes and Digestive and Kidney Diseases, General Clinical Research Centers at the South Carolina Clinical \& Translational Research Institute, at the Medical University of South Carolina (NIH/NCRR UL1RR029882), Children's Hospital and Regional Medical Center (M01RR00037), Colorado Pediatric General Clinical Research Center (M01 RR00069), Barbara Davis Center at the University of Colorado at Denver (DERC NIH P30 DK57516), the Institutional Clinical and Translational Science Award, and NIH/NCRR at the University of Cincinnati (1UL1RR026314-01).

Site Contract Numbers: Kaiser Permanente Southern California (U48/CCU919219, U01 DP000246, and U18DP002714), University of Colorado Denver (U48/CCU819241-3, U01 DP000247, and U18DP000247-06A1), Kuakini Medical Center (U58CCU919256 and U01 DP000245), Children's Hospital Medical Center (Cincinnati) (U48/CCU519239, U01 DP000248, and 1U18DP002709), University of North Carolina at Chapel Hill (U48/ CCU419249, U01 DP000254, and U18DP002708-01), University of Washington School of Medicine (U58/CCU019235-4, U01 DP000244, and U18DP002710-01), and Wake Forest University School of Medicine (U48/CCU919219, U01 DP000250, and 200-2010-35171).

Members of the SEARCH for Diabetes in Youth Study include:

California: Jean M. Lawrence, ScD, MPH, MSSA, Kristi Reynolds, PhD, MPH, Jin-Wen Hsu, PhD, Mary Helen Black, PhD, Kim Holmquist, BA, and Harpreet S. Takhar, MPH, for the Department of Research and Evaluation and Ann K. Kershnar, MD for the Department of Pediatrics, Kaiser Permanente Southern California; and David J. Pettitt, MD, for the Sansum Diabetes Research Institute

Colorado: Dana Dabelea, MD, PhD, Richard F. Hamman, MD, DrPH, Lisa Testaverde, MS, for the Department of Epidemiology, Colorado School of Public Health, University of Colorado Denver, Georgeanna J. Klingensmith, MD, Marian J. Rewers, MD, PhD, David Maahs, MD and Paul Wadwa, MD for the Barbara Davis Center for Childhood Diabetes, Stephen Daniels, MD, PhD, Kristen Nadeau, MD, Department of Pediatrics and Children's Hospital, Clifford A. Bloch, MD, for the Pediatric Endocrine Associates, Carmelita Sorrelman, MSPH, Alfreda Beartrack, MSPH for the Navajo Area Indian Health Prevention Program

Hawaii: Beatriz L. Rodriguez, MD, PhD, Beth Waitzfelder, PhD, Wilfred Fujimoto, MD, J. David Curb, MD, Fiona Kennedy, RN, Greg Uramoto, MD, Sorrell Waxman, MD, Teresa Hillier, MD, Richard Chung, MD, for Kuakini Medical Center 
Ohio: Lawrence M. Dolan, MD, Michael Seid, PhD, Elaine Urbina, MD, MS, Debra A. Standiford, MSN, CNP for the Cincinnati Children's Hospital Medical Center

Carolina: Elizabeth J. Mayer-Davis, PhD, Joan Thomas MS, RD for the University of North Carolina, Chapel Hill, Anwar Merchant, ScD, Angela D. Liese, PhD, MPH, Robert R. Moran, PhD, Gladys Gaillard-McBride, RN, CFNP, Deborah Lawler, MT (ASCP), Malaka Jackson, MD for the University of South Carolina, Deborah Bowlby, MD, for the Medical University of South Carolina, James Amrhein, MD, for Greenville Hospital Systems, Pam Clark, MD for McLeod Pediatric Subspecialists, Mark Parker, MD for Pediatric Endocrinology \& Diabetes Specialists, Charlotte, NC

Washington: Catherine Pihoker, MD, Maryam Afkarian, MD, Angela Badaru, MD, Lisa Gilliam, MD, PhD, Irl Hirsch, MD, Lenna L. Liu, MD, MPH, John Neff, MD, and Joyce YiFrazier, PhD for the University of Washington, Beth Loots, MPH, MSW, Rebecca O'Connor, RN, Sue Kearns, RN, Mary Klingsheim, RN, Emil Buscaino, BS, Katherine Cochrane, BS, Onel Martinez, MS, and Sharla Semana, BS, for Seattle Children's Hospital, and Carla Greenbaum, MD for Benaroya Research Institute

Centers for Disease Control and Prevention: Giuseppina Imperatore, MD, PhD, Desmond E. Williams, MD, PhD, Henry S. Kahn, MD, Bernice Moore, MBA, Gregg W. Edward, PhD, Sharon H. Saydah, PhD

National Institute of Diabetes and Digestive and Kidney Diseases, NIH: Barbara Linder, $\mathrm{MD}, \mathrm{PhD}$

Central Laboratory (University of Washington): Santica M. Marcovina, $\mathrm{PhD}, \mathrm{ScD}$, Vinod $\mathrm{P}$. Gaur, $\mathrm{PhD}$, and Jessica Harting

Coordinating Center (Wake Forest University School of Medicine): Ronny Bell, $\mathrm{PhD}, \mathrm{MS}$, Ralph D'Agostino, Jr., PhD, Bettina Beech, PhD, Douglas Case, PhD, Jasmin Divers, PhD, Timothy Morgan, PhD, Michelle J. Naughton, PhD, Leora Henkin, MPH., MEd, Susan Moxley, BS, Gena Hargis, MPH, Donna Kronner, Maureen T. Goldstein, BA, Andrea Anderson, MS, Jeanette Andrews, MS, Abigail Lauer, MS, Jennifer W. Talton, MS 


\section{Figure 1a}

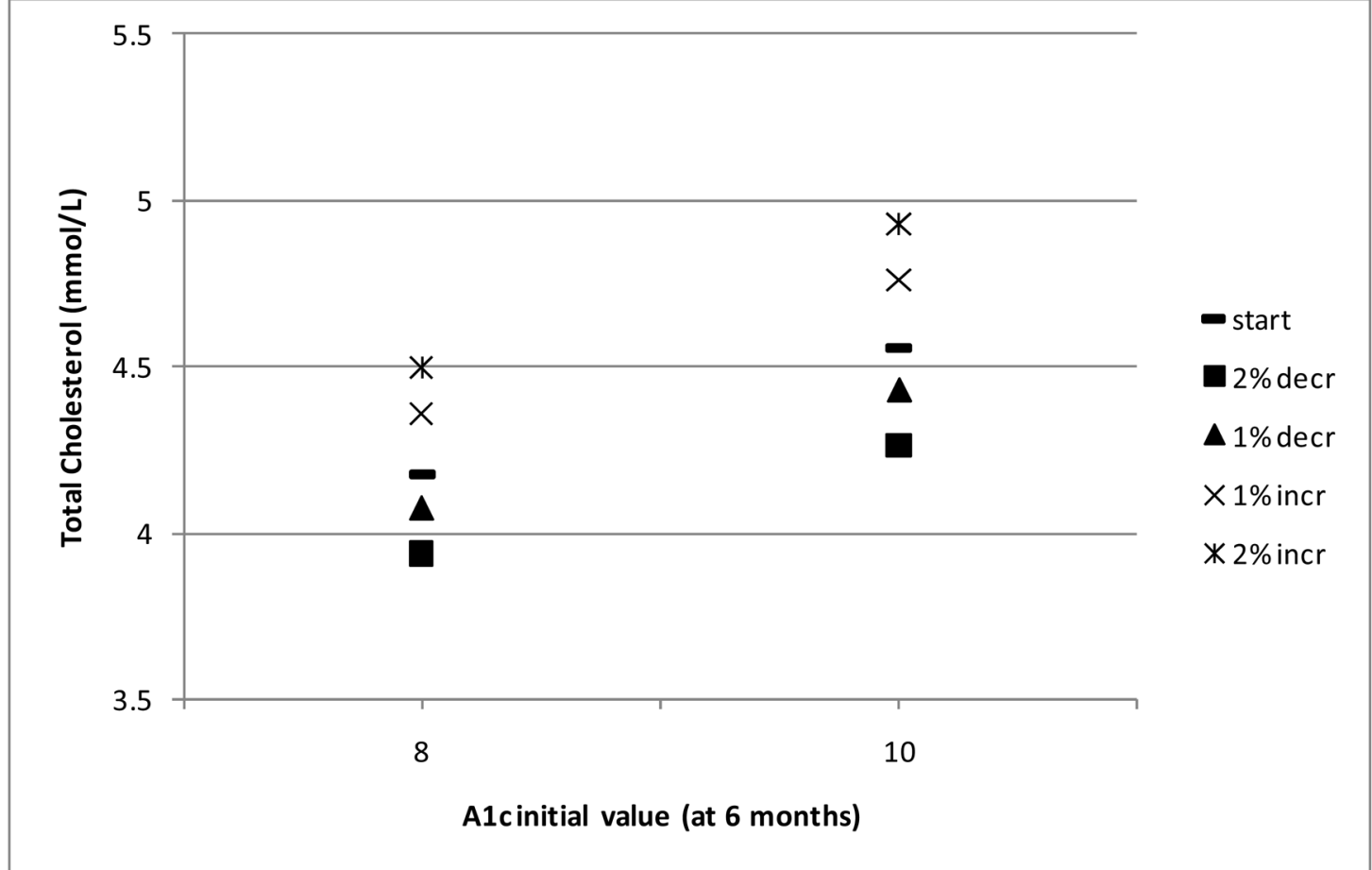




\section{Figure $1 b$}

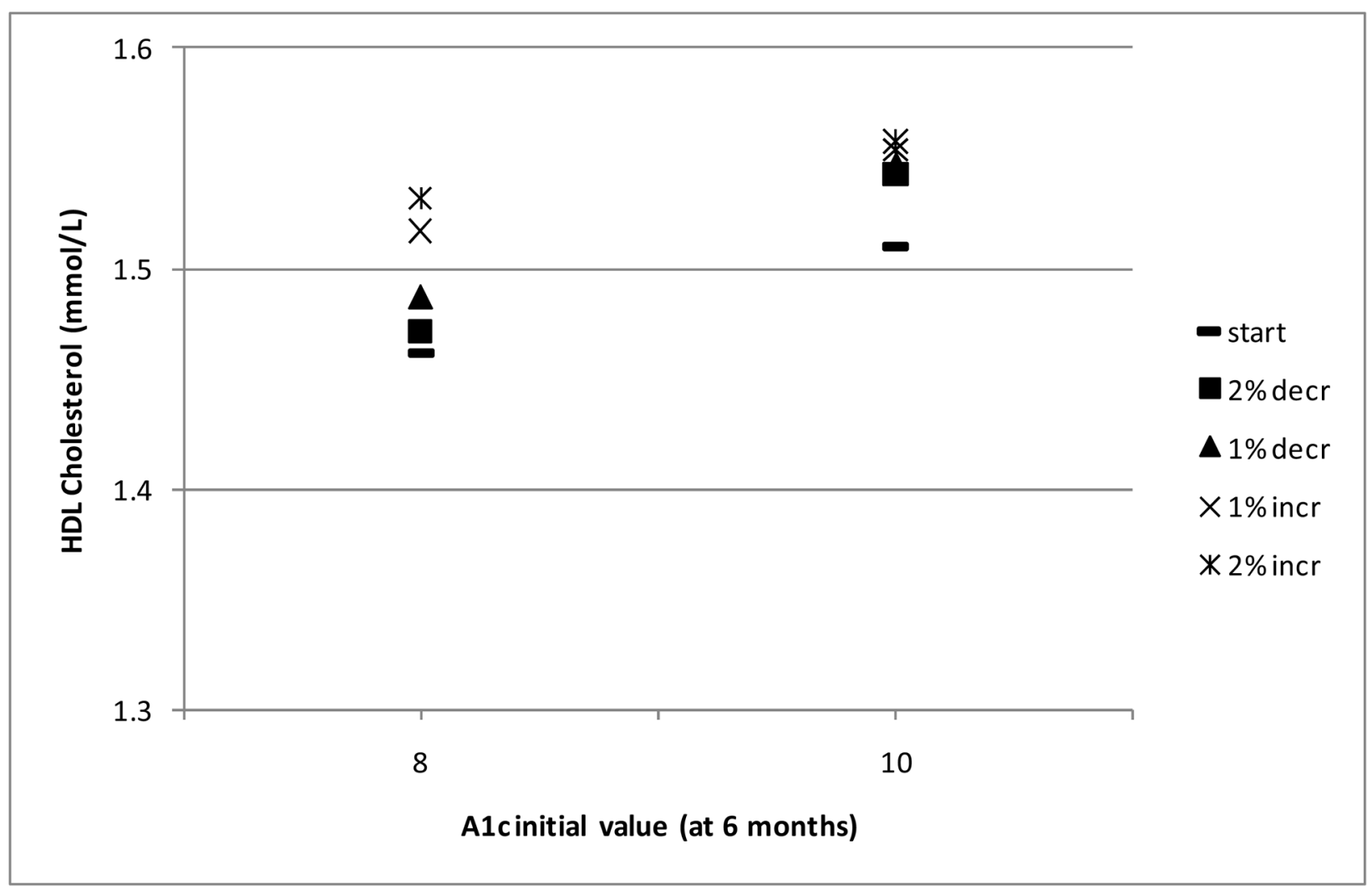

Figure 1c

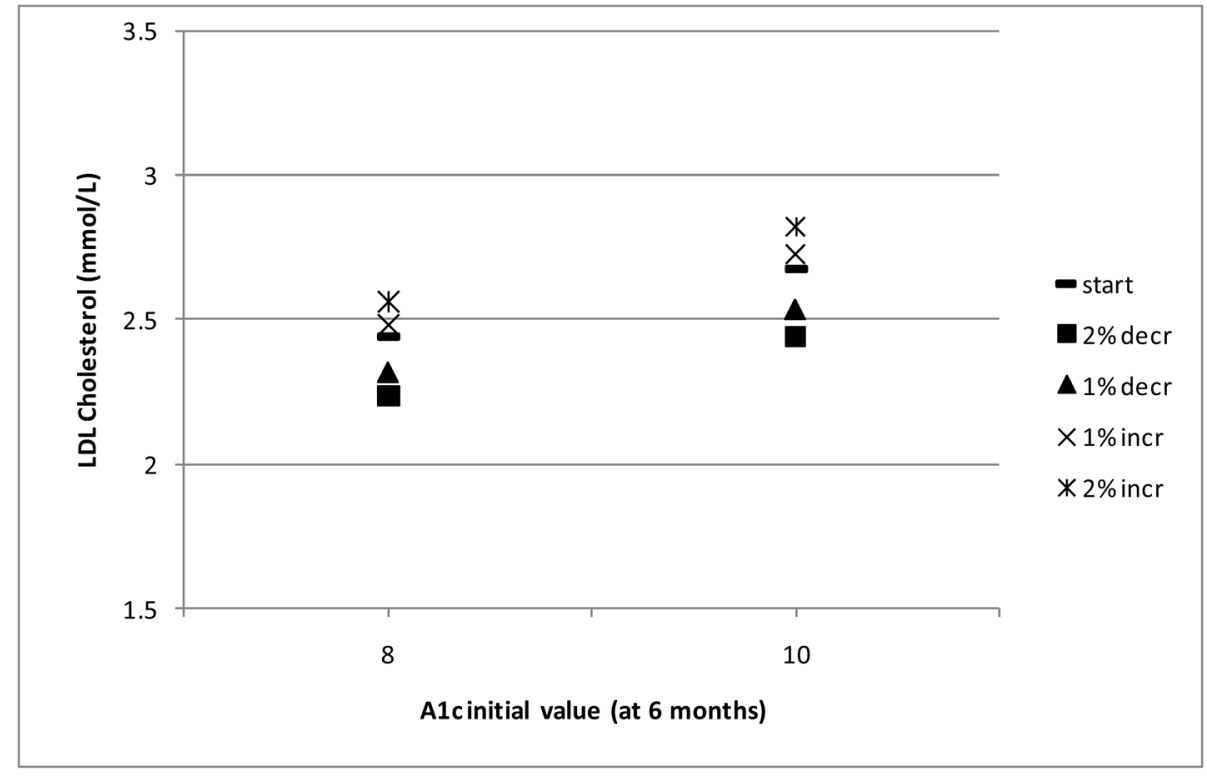

J Pediatr: Author manuscript; available in PMC 2014 January 01. 


\section{Figure 1d}

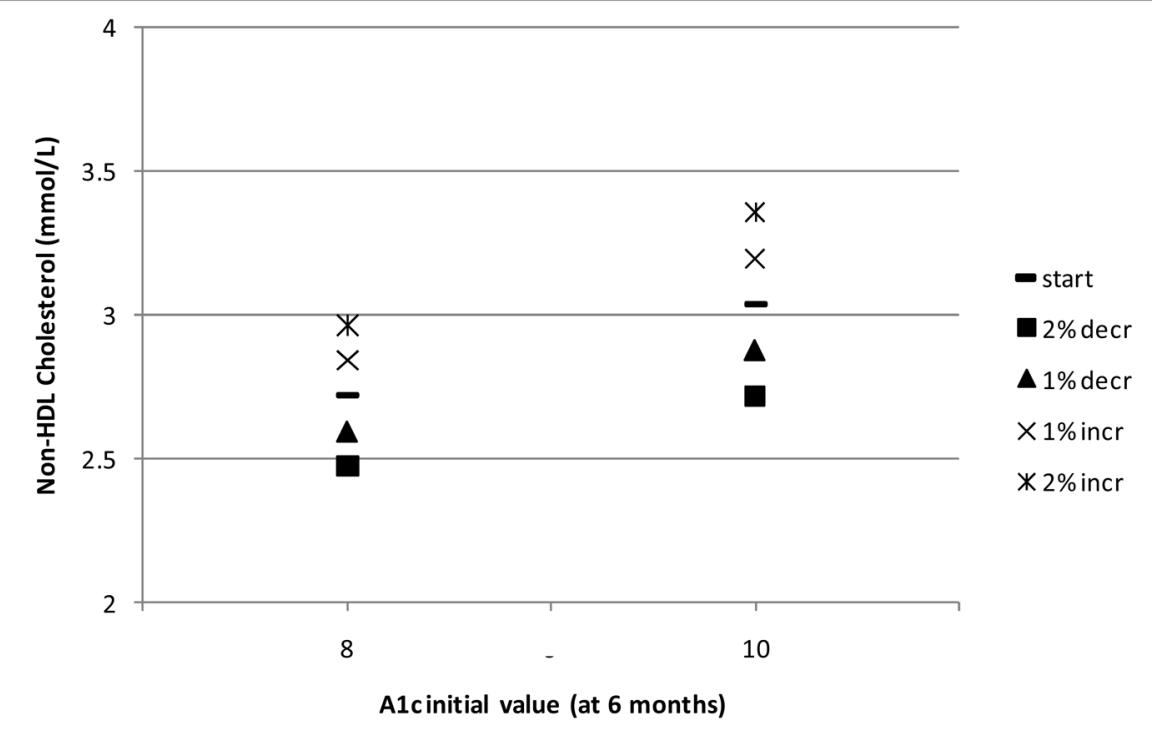

\section{Figure 1e}

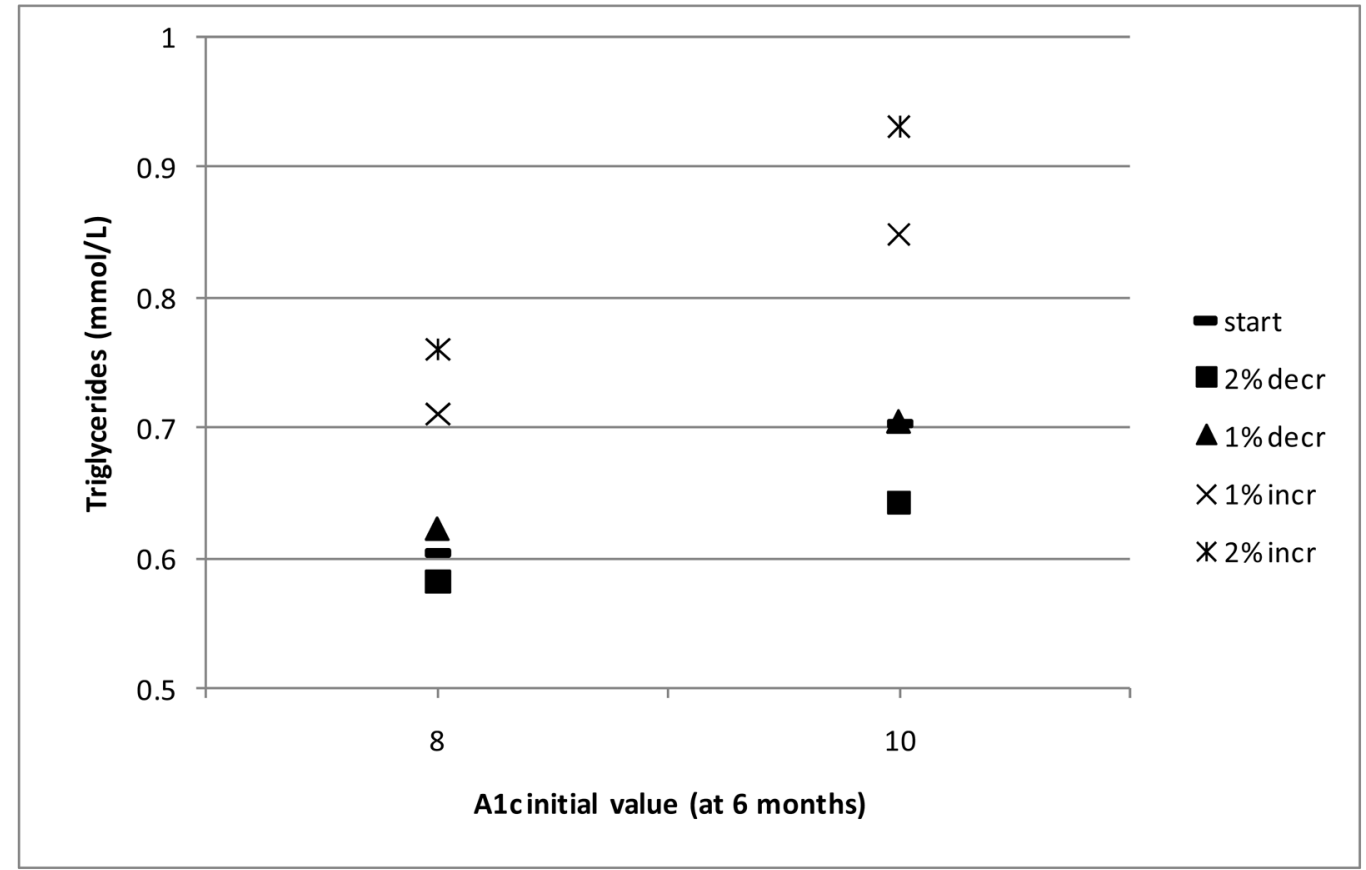

Figure 1.

Figure 1a: Estimated Total cholesterol resulting from change in A1c after a 24 month interval

Figure 1b: Estimated HDL cholesterol resulting from change in A1c after a 24 month interval

Figure 1c: Estimated LDL cholesterol resulting from change in A1c after a 24 month interval 
Figure 1d: Estimated non-HDL cholesterol resulting from change in A1c after a 24 month interval

Figure 1e: Estimated Triglycerides resulting from change in A1c after a 24 month interval 
Table 1

Initial Characteristics of Youth with Type 1 Diabetes $(\mathrm{N}=1193)$

\begin{tabular}{|l|l|}
\hline Variable & Initial in-person visit mean \pm SD or N, \% \\
\hline Age at visit, years & $10.6 \pm 4.1$ \\
\hline T1D duration, months & $10.3 \pm 7.4$ \\
\hline Sex, $\mathrm{n}, \%$ female & $569,48 \%$ \\
\hline Race/ethnicity, $\mathrm{n}, \%$ & \\
\hline Asian-Pacific Islander & $38,3.2 \%$ \\
\hline Non-Hispanic Black & $113,9.5 \%$ \\
\hline Hispanic & $131,11.0 \%$ \\
\hline American Indian & $4,0.3 \%$ \\
\hline Non-Hispanic White & $907,76.0 \%$ \\
\hline A1c, \% & $7.7 \pm 1.4$ \\
\hline BMI, z-score (N=1135) & $0.55 \pm 0.98$ \\
\hline Waist Circumference, cm (N=1124) & $70.2 \pm 14.0$ \\
\hline Insulin dose per kg (N=1113) & $0.63 \pm 0.42$ \\
\hline Total Cholesterol, mmol/l & $4.17 \pm 0.76$ \\
\hline HDL-c, mmol/1 & $1.39 \pm 0.33$ \\
\hline LDL-c, mmol/1 & $2.45 \pm 0.63$ \\
\hline TG, median (Q1,Q3), mmol/l & $0.62(0.47,0.81)$ \\
\hline Non-HDL-c, mmol/1 & $2.78 \pm 0.69$ \\
\hline Total Cholesterol, mg/dL & $161 \pm 29$ \\
\hline HDL-c, mg/dL & $54 \pm 13$ \\
\hline LDL-c, mg/dL & $95 \pm 24$ \\
\hline TG, median (Q1,Q3), mg/dL & $55(42,72)$ \\
\hline Non-HDL-c, mg/dL & $108 \pm 27$ \\
\hline
\end{tabular}


Table 2

Associations of Change in A1c to Change in Lipids: $\mathrm{mmol} / \mathrm{l}[\mathrm{mg} / \mathrm{dL}]$

\begin{tabular}{|c|c|c|c|c|}
\hline \multirow[t]{2}{*}{ Covariates of interest ${ }^{*}$} & \multirow[b]{2}{*}{ Beta } & \multicolumn{2}{|c|}{$95 \% \mathrm{CI}$} & \multirow[b]{2}{*}{ p-value } \\
\hline & & Lower & Upper & \\
\hline \multicolumn{5}{|l|}{ TC } \\
\hline Initial A1c (\%) & $-0.084[-3.234]$ & $-0.170[-6.559]$ & $0.002[0.092]$ & \\
\hline Time-Dependent A1c (\%) & $0.034[1.307]$ & $-0.033[-1.286]$ & $0.101[3.900]$ & \\
\hline Initial $\times$ TD A1c interaction & $0.013[0.512]$ & $0.005[0.181]$ & $0.022[0.843]$ & 0.0025 \\
\hline T1D duration (month) & $0.002[0.062]$ & $-0.000[-0.002]$ & $0.003[0.126]$ & 0.0572 \\
\hline \multicolumn{5}{|l|}{ HDL-c } \\
\hline Initial A1c (\%) & $0.066[2.569]$ & $0.031[1.192]$ & $0.102[3.946]$ & \\
\hline Time-Dependent A1c (\%) & $0.061[2.360]$ & $0.033[1.275]$ & $0.089[3.444]$ & \\
\hline Initial $\times$ TD A1c interaction & $-0.006[-0.222]$ & $-0.009[-0.360]$ & $-0.002[-0.084]$ & 0.0016 \\
\hline T1D duration (month) & $0.002[0.652]$ & $0.001[0.038]$ & $0.002[0.093]$ & $<0.0001$ \\
\hline \multicolumn{5}{|l|}{ LDL-c } \\
\hline Initial A1c (\%) & $-0.034[-1.326]$ & $-0.104[-4.022]$ & $0.035[1.371]$ & \\
\hline Time-Dependent A1c (\%) & $0.027[1.041]$ & $-0.027[-1.032]$ & $0.081[3.114]$ & \\
\hline Initial $\times$ TD A1c interaction & $0.007[0.266]$ & $-0.000[-0.001]$ & $0.014[0.532]$ & 0.0506 \\
\hline T1D duration (month) & $-0.002[-0.067]$ & $-0.003[-0.116]$ & $-0.001[-0.019]$ & 0.0062 \\
\hline \multicolumn{5}{|l|}{ Non-HDL-c } \\
\hline Initial A1c (\%) & $-0.149[-5.761]$ & $-0.227[-8.794]$ & $-0.071[-2.728]$ & \\
\hline Time-Dependent A1c (\%) & $-0.025[-0.974]$ & $-0.086[-3.336]$ & $0.036[1.387]$ & \\
\hline Initial $\times$ TD A1c interaction & $0.018[0.713]$ & $0.011[0.411]$ & $0.026[1.015]$ & $<0.0001$ \\
\hline T1D duration (month) & $-0.000[-0.002]$ & $-0.002[-0.060]$ & $0.001[0.056]$ & 0.94 \\
\hline \multicolumn{5}{|l|}{ TG $(\log )^{* *}$} \\
\hline Initial A1c (\%) & -0.121 & -0.171 & -0.070 & \\
\hline Time-Dependent A1c (\%) & -0.037 & -0.078 & 0.003 & \\
\hline Initial $\times$ TD A1c interaction & 0.013 & 0.008 & 0.018 & $<0.0001$ \\
\hline T1D duration (month) & 0.004 & 0.003 & 0.005 & $<0.0001$ \\
\hline
\end{tabular}

Multivariable model also adjusts for: site, BMI z-score, gender, race/ethnicity, age and age $^{2}$, and season of the year **

Coefficients are unchanged since log-transformation means that unit conversion is captured in the intercept term 